\title{
On the Change of the Constituents of the Urine after Section of the Renal Nerve.
}

\author{
$\mathrm{BY}$ \\ RYOICHI YOSHIMURA. \\ (吉 村 豆一) \\ (From the Pharnacological Laboratory of the Tohoku Imperial. \\ University, Sendai.)
}

It has been ascertained by many experiments that there exist in the renal nerve the vasomotor nerve fibres which supply the blood vessel of the kidneys. But whether or not there are also special nerve fibres which supply the secretory cells is not clear.

As the kidneys have glandular structure, the existence of special secretory nerve fibres for the kidneys, besides vaso-motor nerve fibres, as other typical glands, is supposed by some authors as possible. But the kidneys are genetically different from other typicai glands. While the latter develops mainly from the enderm or the epiderm, the former mainly from the mesoderm. Moreover the kidneys are functionally different from the typical glands. For, while the typical gland secretes matters which are specially formed in the cells of the gland, the kidneys excrete matters which are derived unchanged from the blood, except a small amount of hippuric acid.

Since the kidneys are genetically and functionally different from the typical glands, in explaining the nerve supplying them, we need not seek the analogy of the glands. Moreover, because the attempts to prove the existence of a special secretory nerve have all failed, its existence is very much doubted.

Recently Phode and Ellinger ${ }^{13}$ reported that they have succeeded in proving the existence of special secretory nerve fibres in 
the renal nerve. According to their experiments, when the renal nerve of one side of an animal was cut off, the quantity of the urine flowed from that side was found very much greater than that of the other side and while the concentration of the constituents of the urine flowed from the impaired side became lower, its total amount increased. They maintain that this difference was caused by the section of the inhibitory secretory nerve fibres which exist in the renal nerve. But the increase of the urine flow is also caused by the facilitation of the renal circulation (Gall, Hermann). Now when the vaso-motor nerve fibres in the renal nerve are divided the renal blood vessels of that side dilate, so that the blood flow through the kidney accelerates (Burton-Opitz and Lucas ${ }^{2}$ ). Therefore we can not safely conclude that the increase of the urine flow in the above experiments was caused by the section of the inhibitory secretory nerve fibres, unless we discount the increase due to the dilatation of the renal blood vessels. Moreover, the concentration of the constituents of the urine is not constant even in the normal condition.

According to the experiment of $\mathrm{Cushny}{ }^{3)}$, the concentration and the total amount of chlorides contained in the urine vary with the increase or decrease of the quantity of the urine. While the total amount of sulphates and urea varies with the increase or decrease of the quantity of the urine, their concentration varies inversely with the quantity of the urine-a more quantity the less concentration, and a less quantity the more concentration. Hence he revised the theory of Ludwig concerning the formation of the urine. All the constituents of the blood serum except colloidal substances are filtered in the glomerules. When this filtrate passes through the tubules, some of its constituents are again absorbed with the resulting change in the concentration of each constituent, when it is finally excreted as the urine. Since the rate of absorption of each constituent depends upon its diffusibility, the concentration of each constituent will undergo various changes according to the rapidity with which the filtrate passes through the tubules. When the quantity of the urine decreases, the rapidity with which the filtrate passes through the tubules decreases, and the time during which each constituent is absorbed lengthens. Accordingly water and readily diffusible substances, such as chlorides, will be absorbed in a large quantity and less duffusible substances, such as sulphates, phosphates and urea, are 
also absorbed, but very little compared with water. Hence their concentration will increase. But when the quantity of the urine increases, the time of absorption of each constituent is shortened, thus the constituents of the urine approach to those of the blood serum. Therefore, for chlorides, both the concentration and the total amount increase and for sulphates, the concentration decreases and the total amount increases. Yagi and Kurodats also noticed the same change in the constituents of the urine by varying the quantity of the urine by regulating the circulation of the kidneys.

Since the concentration of the constituents of the urine has an important relation to the increase or decrease of the quantity of the urine, we would naturally expect the change in the concentration of the constituents of the urine, when the quantity of the urine increases by section of the renal nerve. Therefore, although there is a change in the concentration of the constituents of the urine, we can not infer the existence of the secretory nerve, unless the necessary consequence following the change in the quantity of the urine is taken into account. Hence, in my experiment, I divided the renal nerve of one side of an animal and after having made the urine How of this side approximate to that of the intact side by artificial restriction of the renal artery, tried to examine whether any change in the concentration of the constituents followed.

A rabbit was anaesthetized with urethane, and cannula was inserted into the ureters of both sides, and the urine flowed from both sides was collected separately (First period). The renal nerve of the left side was divided and the quantity of the urine flowing from the left side became coniderably greater than that of the intact side, then the urine of both sides was collected (Second period). 'Then the circulation through the impaired kidney was retarded by compressing the renai artery by means of a screw clamp, and when the quantity of the urine flowing out from this side decreased and approached to that of the intact side, the urine of both sides was collected (Third period). And the depression of the freezing point of the urine of each period was examined. The following is an example.

As appears in the following table, the quantity of the urine of the right side shows the tendency of gradual decrease with a lapse of time. The quantity of the urine of the left side, compared to that 
Rabbit $2 \cdot 4$ kilos.

\begin{tabular}{|c|c|c|c|c|c|c|c|}
\hline \multirow[b]{2}{*}{ Period } & \multirow[b]{2}{*}{$\begin{array}{l}\text { Time when } \\
\text { urine was } \\
\text { collected }\end{array}$} & \multicolumn{3}{|c|}{ Right (intact) side } & \multicolumn{3}{|c|}{ Left (impaired) side } \\
\hline & & $\begin{array}{c}\text { (a) } \\
\text { Quantity } \\
\text { of urine } \\
\text { in c.c. }\end{array}$ & $\begin{array}{c}\text { (b) } \\
\text { Depres- } \\
\text { sion of } \\
\text { freezing } \\
\text { point }\end{array}$ & $a \times b$ & $\begin{array}{c}\text { (a) } \\
\text { Quantity } \\
\text { of urine } \\
\text { in c.c. }\end{array}$ & $\begin{array}{c}\text { (b) } \\
\text { Depres- } \\
\text { sion of } \\
\text { freezing } \\
\text { point }\end{array}$ & $a \times b$ \\
\hline I Period & $9.00-10.00$ & $3 \cdot 9$ & $1 \cdot 42$ & 5.54 & $4 \cdot 1$ & $1 \cdot 39$ & $5 \cdot 70$ \\
\hline II Period & $12.00-1.00$ & $3 \cdot 0$ & 1.59 & $4 \cdot 77$ & $7 \cdot 8$ & 0.99 & $7 \cdot 72$ \\
\hline III Period & $1.80-2.30$ & $2 \cdot 5$ & 1.72 & $4 \cdot 30$ & $2 \cdot 0$ & 1.78 & $3 \cdot 56$ \\
\hline
\end{tabular}

of the right side was a little greater in the first period, and became two and a half times more in the second period and a little less in the third period. The depression of the freezing point of the urine of the right side gradually increased with the decrease of the quantity of the urine. The depression of the freezing point of the left side was least in the second period when the quantity of the urine was greatest, and greatest in the third period when the quantity of the urine was least. If we compare the two sides we find that in the first period, the quantity of the urine was about the same and the depression of the freezing point also about the same although it was a little less in the left side where the quantity of the urine was a little greater; in the second period, the quantity of the urine of the left side was considerably greater and the depression of the freezing point considerably less; in the third period, the quantity of the urine of both sides was about the same, and the depression of the freezing point also about the same, although it was a little less in the right side where the quantity of the urine was a little greater. Thus it was clear that in the second period or after section of the renal nerve, the depression of the freezing point was considerably less than that of the intact side. This result agrees with the experiment of Rhode and Ellinger. But if these changes were due to the loss of a special nerve function as they maintain, the same difference, in the urine of both sides must have been observed in the third period when the quantity of the urine flowed out from the impaired side was made to approach to that of the intact side by an artificial restriction of the flow of the blood. But contrarily, the result of the experiment showed that there was no such difference between two sides as was seen in the first period or before the renal nerve was divided. 
From this, it is to be seen that the decrease of the depression of the freezing point of the urine after the section of the renal nerve had no direct relation with the section of that nerve, but it was the indirect result due to the increase of the quantity of the urine which was caused by the accelerated flow of the blood through the kidney after the section of the renal nerve.

In this experiment, the total amount of the constituents of the urine was not measured. But the number of molecules as may be conjectured by the table (5.\& 8. columns), varied according to the increase or decrease of the quantity of the urine. In the second period, in spite of the decrease of the depression of the freezing point of the urine of the impaired side, the sum total of molecules was great. In the third period, when the quantity and the depression of the freezing point of the urine of both sides were about the same, the sum total of molecules was also about the same. Therefore this change was evidently due to the change of the quantity of the urine and has no direct bearing on the section of the renal nerve.

Since the concentration and the total amount of the urine constituents vary in accordance with the quality of each constituent, we can not know the state of excretion of each constituent by merely measuring the depression of the freezing point or the specific gravity of the urine. To know it, it must be estimate each constituent of the urine separately. For this purpose the quantity of two kinds of substance which differ in diffusibility, i.e. chlorides and sulphates was estimated and examined whether or not the section of the renal nerve had the direct relation to the excretion of these substances. In this experiment a large quantity of the urine was needed. So a dog was used. A mixed solution of $\frac{\mathrm{N}}{15}$ sodium chloride and $\frac{\mathrm{N}}{15}$ sodium sulphate was infused into the vein with a definite rapidity so as to secure the increase of the quantity of the urine. The section of the renal nerve and the ligation of the blood vessel were the same as the case of the rabbit. Chlorides in the urine were estimated according to the method of Volhard. Sulphates were estimated as barium sulphate. Chlorides were calculated as sodium chloridsese and sulphates as sodium sulphate.

Dog. 15.0 kilos. Anaesthetization with A.E.C. mixture after the subcutaneous injections of morphine. During the experiment, the saline solution was infused at the rate of 1.0 c.c. in 10 minutes. The first period: before the renal nerve was divided. 
The second period: after it was divided. The third period: aftr the blood ressel of the kidney was compressed.

\begin{tabular}{|c|c|c|c|c|c|c|c|c|c|c|c|}
\hline \multirow{3}{*}{ Period } & \multirow{3}{*}{$\begin{array}{l}\text { Time during } \\
\text { which urine } \\
\text { was } \\
\text { collected }\end{array}$} & \multicolumn{5}{|c|}{ Right (intact) side } & \multicolumn{5}{|c|}{ Left (impaired) side } \\
\hline & & \multirow{2}{*}{$\begin{array}{l}\text { Quant- } \\
\text { ity of } \\
\text { urine } \\
\text { in c.c. }\end{array}$} & \multicolumn{2}{|c|}{$\begin{array}{l}\text { Sodium } \\
\text { chloride } \\
\end{array}$} & \multicolumn{2}{|c|}{$\begin{array}{l}\text { Sodium } \\
\text { sulphate }\end{array}$} & \multirow{2}{*}{$\begin{array}{l}\text { Quant- } \\
\text { ity of } \\
\text { urine } \\
\text { in ccm }\end{array}$} & \multicolumn{2}{|c|}{$\begin{array}{l}\text { Sodium } \\
\text { shloride }\end{array}$} & \multicolumn{2}{|c|}{$\begin{array}{l}\text { Sodium } \\
\text { sulphate }\end{array}$} \\
\hline & & & 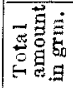 & 施 & 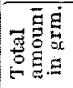 & 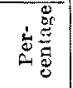 & & 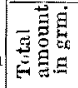 & 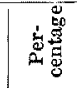 & 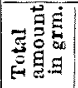 & 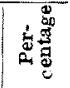 \\
\hline I Period & $10.00-10.30$ & $19 \cdot 0$ & 0.011 & $0 \cdot 055$ & 0.342 & 1.758 & $30 \cdot 3$ & 0.012 & 0.060 & $0 \cdot 346$ & 1.702 \\
\hline II Period & $1.30-2.00$ & 10.8 & 0.005 & 0.044 & 0.227 & $2 \cdot 101$ & $32 \cdot 4$ & 0.037 & 0.115 & $0.434 \mid$ & $1 \cdot 338$ \\
\hline III Period & $2.30-3.00$ & $25 \cdot 1$ & 0.026 & 0.105 & 0.474 & $1 \cdot 188$ & $23 \cdot 5$ & 0.024 & 0.100 & 0.448 & 1.909 \\
\hline
\end{tabular}

In the first period, the quantities of the urine of both sides were about the same and the total amount and the percentage of sodium chloride and sodium sulphate also about the same. In the second period, after the section of the renal nerre, the quantity of the urine of the impaired side was three times as much as that of the intact side. The total amount and the percentage of sodium chlorid contained in the urine of the impaired side made a considerable increase. But while the total amount of sodium sulphate increased, its percentage decreased. In the third period, or after the ligation of the blood vessel, the quantity of the urine of the both sides were about the same and the total amount and the percentage of chloride became nearly the same. In other words, when the renal nerve was divided, the quantity of the urine of that side increased and a great increase in the quantity of chloride followed. But when the quantity of the urine of the impaired side was made equal by the ligation of the blood vessel with that of the intact side, no such change was seen. Hence the change, was the result of the increased quantity of the urine due to the accelerated flow of the blood of the kidney.

To conclude, the increase of the urine after section of the renal nerve must be due to the acceleration of the renal circulation, cansed by the loss of vasoconstrictor impulse of the renal nerve. The change of the constituents of the urine is the necessary outcome accompanying the increase of the quantity of the urine and not to be ascriballe to the loss of the impulse of the inhibitory secretory nerve. 


\section{REFERENCES.}

1) Rohde u. Ellinger, Zentralbl. f. Physiol. Bd. 27, S. 12, 1913.

2) Burton-Opitz u. Lucas, Pflüger's Arch. Bd. 123, S. 553, 1908; Bd. 125, S. 221, 1908; Bd. 127, S. 142, 1908.

3) Cushny, Journ. of Physiol. 27, p. 429, 1901.

4) Yagi and Kuroda, Journ. of Physiol. 49, p. 162, 1915. 